\title{
The Research of the Smart Growth Based on AHP
}

\section{Chuxuan Zhang}

\author{
School of Environmental Science and Engineering, North China Electric Power University, \\ Baoding 071003, China \\ 527469028@qq.com
}

\begin{abstract}
With the consistent growth population and urbanization, the concept of sustainable development will play an more and more indispensable role in city construction. In this paper, we set up fuzzy comprehensive evaluation model based on AHP.We begin to choose some indicators to build a metric to measure the success of smart growth, including GDP, employment rate, the proportion of urban clean energy and etc. Secondly, we set up an evaluation criterion system and select the corresponding national excellent global index in $80 \%$ as the standard of success. Finally, We can use fuzzy comprehensive evaluation model to assess current development plans .
\end{abstract}

Keywords: smart growth;fuzzy comprehensive evaluation model;evaluation criterion system.

\section{Introduction}

"Smart growth is about helping every town and city become a more economically prosperous, socially equitable, and environmentally sustainable place to live." ${ }^{[1]}$ The ten principles for smart growth are ${ }^{[2]}$

1 Mix land uses

2 Take advantage of compact building design

3 Create a range of housing opportunities and choices

4 Create walkable neighborhoods

5 Foster distinctive, attractive communities with a strong sense of place

6 Preserve open space, farmland, natural beauty, and critical environmental areas

7 Strengthen and direct development towards existing communities

8 Provide a variety of transportation choices

9 Make development decisions predictable, fair, and cost effective

10 Encourage community and stakeholder collaboration in development decisions

With the enormous change of global urbanization course, we need to build a sustainable city with smart growth. Aimed to ensure the realization of smart growth, including economic prosperity, social equality and environmental sustainability, sustainable urbanization is becoming more and more important. However, there was no research on the model that can establish the theory of smart growth. Therefore, our task is to build a model to measure the success of smart growth of a city.

\section{Fuzzy comprehensive evaluation model based on AHP}

We attempt to define a metric to measure the success of smart growth of a city.This problem is solved by establishing the AHP fuzzy evaluation model.

\subsection{Establish the indexes to measure smart growth}

We will simplify the problem into three levels: the target layer $\boldsymbol{A}$, criterion layer $\boldsymbol{B}$, scheme layer $\boldsymbol{C}$. Target layer A is the overall purpose of achieving successful city smart growth. The criterion layer $\boldsymbol{B}$ is the three $E^{\prime}$ s principle of sustainability. The scheme layer $\boldsymbol{C}$ is the indicators we selected 
considering the three E's of sustainability and the 10 principles of smart growth. The scheme layer $C$ is the 20 indicators.

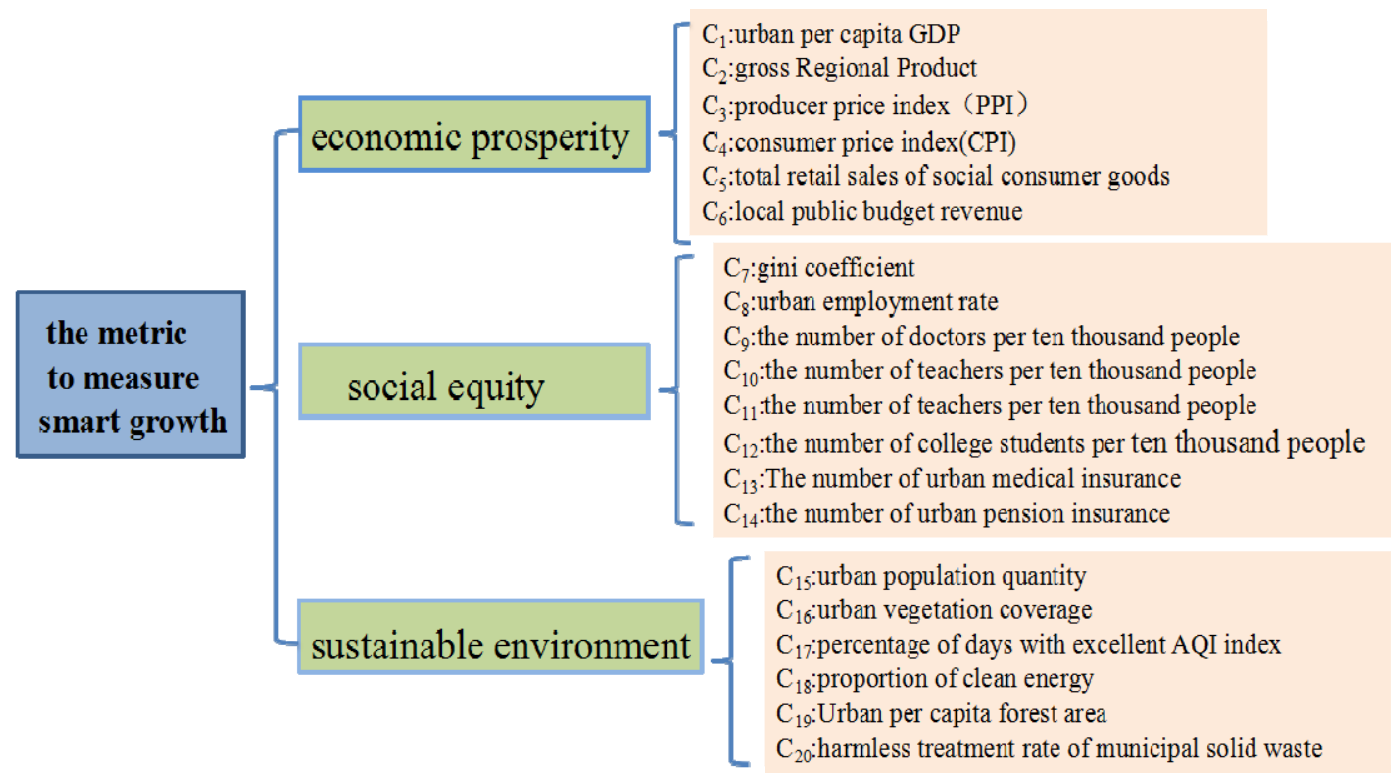

Figure 1: the indexes to measure smart growth

\subsection{Establish judgment matrix.}

Firstly, we analyze the influence of the criterion layer $\boldsymbol{B}$ on the target layer $\boldsymbol{A}$. The criterion layer $\boldsymbol{B}$ the success in this paper is divided into three categories, respectively representing the economic prosperity, social equality and sustainable development. Then,we analyze the influence of the scheme layer $\boldsymbol{C}$ on the criterion layer $\boldsymbol{B}$. Later,we use $\boldsymbol{A} \boldsymbol{i j}$ to show the relative importance. We conducted a survey among 1000 people to choose the relative importance of the index they think.

Table 1 The Definition of Relative Importance

\begin{tabular}{|c|c|}
\hline Relative Importance aij & Definition \\
\hline 1 & $\mathrm{Xi}$ is equivalent to $\mathrm{Xj}$, assignment: 1 \\
\hline 3 & $\mathrm{Xi}$ is more important than $\mathrm{Xj}$, assignment: 3 \\
\hline 5 & $\mathrm{Xi}$ is much more important than $\mathrm{Xj}$, assignment: 5 \\
\hline 7 & $\mathrm{Xi}$ is far more important than $\mathrm{Xj}$, assignment: 7 \\
\hline 9 & $\mathrm{Xi}$ is the most important \\
\hline $2,4,6,8$ & the level of importance is between $\mathrm{Xi}$ and $\mathrm{Xj}$ \\
\hline $1 / 2 、 1 / 3, \ldots \ldots . .1 / 9$ & $\begin{array}{l}\text { the relationship between } \mathrm{Xi} \text { and } \mathrm{Xj} \text { corresponding to the } \\
\text { above levels }\end{array}$ \\
\hline
\end{tabular}

1) Comparing to economic prosperity, social equity and sustainable development, We obtain approximate results:

$$
A_{12}=1 / 3 ; A_{13}=1 / 4 ; A_{23}=1 / 2 ; A_{21}=3 ; A_{31}=4 ; A_{32}=2 ;
$$

Thus, the positive and negative reciprocal matrix:

$$
E=\left|\begin{array}{ccc}
1 & 1 / 3 & 1 / 4 \\
3 & 1 & 1 / 2 \\
4 & 2 & 1
\end{array}\right|
$$

Consistency test: $\mathrm{CR}=\mathrm{CI} / \mathrm{RI}=0.0158<0.1$

So its weight vector is: $\quad W=(0.1220,0.3196,0.5584)^{T}$ 
2) We construct the positive and negative matrices of each criterion of the criterion layer $\boldsymbol{B}$. The positive and negative matrix E1 about $\mathrm{C} 1 、 \mathrm{C} 2 、 \mathrm{C} 3 、 \mathrm{C} 4 、 \mathrm{C} 5 、 \mathrm{C} 6$ :

$$
\mathbf{E 1}=\left|\begin{array}{llllll}
1 & \frac{1}{4} & \frac{1}{5} & \frac{1}{2} & \frac{1}{5} & \frac{1}{5} \\
4 & 1 & \frac{1}{2} & 2 & 1 & 1 \\
5 & 2 & 1 & 3 & 1 & 1 \\
2 & \frac{1}{2} & \frac{1}{3} & 1 & \frac{1}{2} & \frac{1}{2} \\
5 & 1 & 1 & 2 & 1 & 1 \\
5 & 1 & 1 & 2 & 1 & 1
\end{array}\right|
$$

Consistency test: $\mathrm{CR}=\mathrm{CI} / \mathrm{RI}=0.0083<0.1$

So its weight vector is:

$$
W 1=(0.0452,0.1821,0.2565,0.0946,0.2108,0.2108)^{T}
$$

The calculation formula of economic prosperity index:

$$
\varphi_{a}=\sum_{i=1}^{6} C i W_{a i}
$$

The positive and negative matrix E2 about C7、C8、C9、C10、C11、C12、C13、C14:

$$
\mathbf{E 2}=\left|\begin{array}{llllllll}
1 & \frac{1}{3} & \frac{1}{5} & \frac{1}{7} & \frac{1}{3} & \frac{1}{3} & \frac{1}{4} & \frac{1}{4} \\
3 & 1 & \frac{1}{5} & \frac{1}{5} & \frac{1}{6} & \frac{1}{6} & \frac{1}{3} & \frac{1}{3} \\
5 & 5 & 1 & \frac{1}{2} & \frac{1}{3} & \frac{1}{3} & 1 & 1 \\
7 & 5 & 2 & 1 & \frac{1}{2} & 1 & 3 & 3 \\
8 & 6 & 3 & 2 & 1 & 1 & 3 & 3 \\
8 & 6 & 3 & 1 & 1 & 1 & 3 & 3 \\
4 & 3 & 1 & \frac{1}{3} & \frac{1}{3} & \frac{1}{3} & 1 & 1 \\
4 & 3 & 1 & \frac{1}{3} & \frac{1}{3} & \frac{1}{3} & 1 & 1
\end{array}\right|
$$

Consistency test: $\mathrm{CR}=\mathrm{CI} / \mathrm{RI}=0.0217<0.1$

So its weight vector is:

$$
W 2=(0.0224,0.0363,0.0996,0.1936,0.2517,0.2282,0.0841,0.0841)^{T}
$$

The calculation formula of social equity index:

$$
\varphi_{b}=\sum_{i=7}^{14} C i W_{b i}
$$

The positive and negative reciprocal matrix E3 about $\mathrm{C} 15, \mathrm{C} 16 、 \mathrm{C} 17, \mathrm{C} 18, \mathrm{C} 19, \mathrm{C} 20$ : 


$$
\mathrm{E} 3=\left|\begin{array}{llllll}
1 & 2 & 1 & \frac{1}{2} & \frac{1}{3} & \frac{1}{2} \\
\frac{1}{2} & 1 & 1 & 1 & \frac{1}{2} & 1 \\
1 & 1 & 1 & \frac{1}{2} & \frac{1}{2} & \frac{1}{2} \\
2 & 1 & 2 & 1 & \frac{1}{2} & \frac{1}{2} \\
3 & 2 & 2 & 2 & 1 & 3 \\
2 & 1 & 2 & 2 & \frac{1}{3} & 1
\end{array}\right|
$$

Consistency test: $\mathrm{CR}=\mathrm{CI} / \mathrm{RI}=0.0541<0.1$

So its weight vector is:

$$
W 3=(0.1177,0.1238,0.1064,0.1539,0.3138,0.1845)^{T}
$$

The calculation formula of sustainable environment index: $\quad \varphi_{c}=\sum_{i=15}^{20} C i W_{c i}$

3) Calculate the weight vector of the program layer to the target layer $\mathrm{A}$ $\mathrm{W}=(0.0055,0.0222,0.0313,0.0115,0.0257,0.0257,0.0072,0.0116,0.0318$, $0.0619,0.0805,0.0729,0.0269,0.0269,0.0657,0.0691,0.0594,0.0859,0.1753$, $0.1030)^{\mathrm{T}}$



Figure 2: the weight vector of the program layer to the target layer $\mathrm{W}$

4) Establish indicators to measure the success rate of urban intelligent growth. We'll define smart growth $\mathrm{M}$.

$$
M=\emptyset_{a} W 1+\emptyset_{b} W 2+\emptyset_{c} W 3
$$

5) Meanwhile, we found that the AQI index (C17) was negatively correlated with the intelligence growth index. So we adjust the results. 


$$
\emptyset_{c}=\sum_{i=15}^{20} C i W_{c i}-2 \sum_{i=17} C i W_{c i}
$$

\section{3 .Set up an evaluation criterion system}

The evaluation criterion system is based on some developed cities in the world, where the environment, economy, social security other aspects are at the top level. The corresponding values are translated into the same unit by weight conversion out of their corresponding index value. We take the $80 \%$ of the index as the lower limit of success.when the value is between $60 \% \sim 80 \%$,we consider to be medium level. When the value is less than $60 \%$, the city's smart growth index is unsuccessful.

Table 2: Fuzzy Comprehensive Evaluation Model

\begin{tabular}{c|c|c|c|c|} 
Evaluation & Economic Index & Social Equity Index & $\begin{array}{c}\text { Environmental } \\
\text { Sustainability } \\
\text { Index }\end{array}$ & Smart Growth Index \\
\hline Successful & $\geqslant 1200$ & $\geqslant 90$ & $\geqslant 100$ & $\geqslant 1390$ \\
\hline Iledium & $900-1200$ & $90-65$ & $75-100$ & $1040-1390$ \\
\hline Unsuccessful & $\leqslant 900$ & $\leqslant 65$ & $\leqslant 75$ & $\leqslant 1040$ \\
\hline
\end{tabular}

\section{Conclusions}

From the result above, we can get fuzzy comprehensive evaluation model based on AHP.From the above results, we can get a fuzzy comprehensive evaluation model based on AHP. If we take a country as an example, we evaluate the degree of smart growth. Firstly, we collect the values of the 20 indicators in this country. Then,we multiply the value and weight by the economic factor index, the social equity index, and the sustainable development index. Finally, compared with the evaluation criteria, we can evaluate the degree of smart growth associated with three E's principles.

\section{References}

[1]EPA, “This is Smart Growth.” 2016.

https:/www.epa.gov/smartgrowth/smart-growth-publication Reference to a book:

[2] EPA, "Smart Growth: A Guide to Developing and Implementing Greenhouse Gas Reductions Programs." 2011.

http:/www.sustainablecitiesinstitute.org/Documents/SCI/Report_Guide/Guide_EPA_SmartGro wthGHGReduction_2011.pdf 